\title{
Prediction Model for Graft Survival After Liver Transplantation Using Aspartate Aminotransferase, Total Bilirubin and Coagulation Factor: ABC Model
}

\author{
Jinsoo Rhu \\ Samsung Medical Center, Sungkyunkwan University School of Medicine \\ Jong Man Kim ( $\nabla$ yjongman21@gmail.com) \\ Samsung Medical Center, Sungkyunkwan University School of Medicine \\ Kyunga Kim \\ Samsung Medical Center \\ Heejin Yoo \\ Samsung Medical Center \\ Gyu-Seong Choi \\ Samsung Medical Center, Sungkyunkwan University School of Medicine \\ Jae-Won Joh \\ Samsung Medical Center, Sungkyunkwan University School of Medicine
}

\section{Research Article}

Keywords: liver transplantation, graft failure, prediction model

Posted Date: March 17th, 2021

DOI: https://doi.org/10.21203/rs.3.rs-292194/v1

License: (a) (i) This work is licensed under a Creative Commons Attribution 4.0 International License. Read Full License 


\section{Abstract}

Background: This study was designed to build models predicting graft survival after liver transplantation.

Methods: Cox regression model for predicting graft survival after liver transplantation using post-transplantation aspartate aminotransferase, total bilirubin, and international normalized ratio of prothrombin time was constructed. The model was compared with Model for Early Allograft Function Scoring (MEAF) and early allograft dysfunction (EAD) criteria.

Results: The $\mathrm{C}$-index of the model for living donor $(0.73, \mathrm{Cl}=0.67-0.79)$ was significantly higher compared to those of both $\mathrm{MEAF}$ score $(0.69, \mathrm{P}=0.03)$ and EAD criteria. $(0.66, \mathrm{P}=0.001)$ while $\mathrm{C}$-index for deceased donor $(0.74, \mathrm{Cl}=0.65-0.83)$ was significantly higher compared to $\mathrm{C}$-index of $\mathrm{EAD}$ criteria.

$(0.66, P=0.002)$ Time-dependent AUC at 4 weeks of living donor model $(0.93, \mathrm{Cl}=0.86-0.99)$ was significantly higher compared to those of both $\mathrm{MEAF}$ score $(0.87, \mathrm{P}=0.02)$ and EAD criteria. $(0.84, \mathrm{P}=0.02)$ Time-dependent $\mathrm{AUC}$ at 4 weeks of deceased donor model $(0.94, \mathrm{Cl}=0.89-1.00)$ was significantly higher compared to both MEAF score $(0.82, P=0.02)$ and EAD criteria. $(0.81, P<0.001)$ Internal validation for both living donor $(C$-index $=0.68, A U C$ at 2 weeks $=0.91$, AUC at 4 weeks $=0.92)$ and deceased donor $(C$-index $=0.68, A U C$ at 2 weeks $=0.86$, AUC at 4 weeks $=0.91)$ showed competent results.

Conclusion: The prediction model for graft survival after liver transplantation showed high predictability and validity with higher predictability compared to traditional models.

\section{Introduction}

Liver transplantation (LT) is a life-saving procedure for patients with acute or chronic liver failure and malignancy such as hepatocellular carcinoma. However, due to organ shortage, LT can only be performed in a limited number of patients. Nevertheless, LT is not always successful, and 2.7 to $6.9 \%$ of liver grafts develop graft dysfunction. ${ }^{1-3}$ Dysfunction of the graft, whether the cause is primary or secondary, can lead to death or need for additional liver transplantation. Currently in the United States, the Organ Procurement and Transplant Network (OPTN) set an urgent listing criteria for primary nonfunction of a transplanted liver within 7 days of implantation. ${ }^{4}$ The recipients should be in an anhepatic phase or should have aspartate aminotransferase (AST) $\geq 3000 \mathrm{U} / \mathrm{L}$ and one or both of the following: international normalized ratio (INR) of prothrombin time $\geq 2.5$, or acidosis, defined as arterial $\mathrm{pH} \leq 7.30$ or venous $\mathrm{pH} \leq 7.25$ and/or lactate $\geq 4 \mathrm{mmol} / \mathrm{L}$. However, the criteria of OPTN seem restrictive, and many patients who do not fulfill the criteria experience graft failure.

To overcome these conditions, many clinicians have reported on graft dysfunction which can role as an indicator for future graft failure. ${ }^{1-3,5-10}$ However, the criteria of graft dysfunction vary significantly among studies, and markers for graft dysfunction vary widely, including AST,2,3,5,8 alanine aminotransferase (ALT), ${ }^{1,8,9}$ prothrombin time, ${ }^{2,3,8}$ total bilirubin (TB), ${ }^{11}$ acidosis, ${ }^{12}$ and ammonia. ${ }^{3}$ The time points at which those laboratory values are measured varies significantly among studies but are usually within the first week after LT.2,3,9,13 One of the criteria suggested was early allograft dysfunction (EAD) criteria suggested by Olthoff et al, and modeling early allograft function (MEAF) score. ${ }^{14,15}$ Nevertheless, these models still have limitations to be chosen as indicator for retransplantation of the LT recipient.

Therefore, we designed this study to build a prediction model for predicting allograft survival of which endpoint has been defined as retransplantation of the liver or death due to graft dysfunction with three goals. First, to design both living donor liver transplantation (LDLT) and deceased donor liver transplantation (DDLT) models to predict graft survival using common laboratory tests. The second goal is to compare the predictability with other known models. The third goal is to internally validate the prediction model. The calculating model designed for predicting graft survival will be abbreviated as ABC model by including AST, TB, and INR of prothrombin time which is a coagulation factor.

\section{Methods}

Patients

The study population consisted of adult patients who underwent LT in Samsung Medical Center during the period of 2004 to 2018 . Pediatric LTs were excluded, while both living donor and deceased donor LTs of adult recipients were included. No organs from executed prisoners were used

Data collection

Patient data of demographics, LT surgery, and post-transplantation course including laboratory values of AST, TB, and INR were collected from the date of transplantation to the $7^{\text {th }}$ day post-transplantation.

\section{Graft failure}

Graft failure was defined as failure of the liver allograft, either primary or secondary, due to complications that required re-LT or resulted in death of the recipient. The date of graft failure was defined as the date of re-LT or death. Deaths from causes other than liver failure were not defined as graft failure.

\section{Post-transplantation laboratory values}

AST, TB, and INR were used to predict graft survival. Laboratory values during the first week were used. Since laboratory values during the early posttransplantation period can be influenced by pre-transplantation conditions, some modifications were made. TB and INR levels from the day of LT to post-

Page 2/12 
LT day 2 were not used for the prediction model since TB and INR gradually decrease along the post-LT course even in successful LT. Therefore, for the prediction model, maximum level of AST during the first week (AST max7), maximum level of TB from days 3 to 7 post-LT (TB max3-7), and maximum INR from days 3 to 7 post-LT (INR $\operatorname{max3-7})$ were used to predict graft survival.

\section{Statistical analysis}

The prediction models were built using variables that are clinically familiar and relevant. Two models each for LDLT and DDLT were constructed. After building the models, the two models were compared to MEAF score and EAD criteria by comparing C-index and time dependent area-under-the-curve (AUC) at 2 weeks and 4 weeks. ${ }^{14,15}$ MEAF score was calculated based on the previous study reported by Pareja et al. ${ }^{15}$ The comparing process was performed using R packages 'compareC' and 'timeROC'. Validation process for the chosen modeling process was performed. Internal validation using 20 time repeated 5-fold cross-validations were performed using R package 'survAUC' to calculate the C-statistic and AUC estimator proposed by Uno et al. ${ }^{16}$ Calibration plot was drawn to validate the models through 1000 bootstrap resamples of the same size as the original data. Decision curve analysis to evaluate the clinical usefulness of the models was performed by drawing a decision curve computing the net benefit, and the range of positive net benefit was analyzed.

Statistical analyses were performed using SPSS 20.0 (IBM, Chicago, IL, USA), SAS v9.4 (SAS Institute Inc, Cary, NC, USA), and R 3.6.1 (R Foundation for Statistical Computing, Vienna, Austria) using packages 'rmda' for decision curve analysis and 'rms' for drawing a calibration plot.

\section{Ethical approval}

This study was approved by the Institutional Review Board (IRB) of Samsung Medical Center (IRB No. 2020-02-013).

\section{Informed consent}

The need for informed consent was waived by the IRB of Samsung Medical Center due to the retrospective nature of this study. Investigational methods used in this study were implemented in accordance with the relevant guidelines and regulations of the IRB.

\section{Results}

\section{Characteristics of the patient group}

Table 1 shows the summary of baseline characteristics and post-LT courses of the patient group. A total of 1512 LTs, 1153 LDLTs and 359 DDLTs were included to the study. Most of the recipients were male patients $(78.0 \%, \mathrm{n}=899$ in LDLT and $67.1 \%, \mathrm{n}=241$ in DDLT) with mean age around 52 . (52.8 \pm 8.5 years in LDLT and $51.7 \pm 10.4$ years in DDLT) While mean donor age was $32.7 \pm 11.6$ years in LDLT, mean donor age of DDLT was $46.9 \pm 16.3$ years in DDLT. While only $0.9 \%(n=10)$ of LDLTs were re-LT cases, $13.7 \%(n=49)$ of DDLT cases were re-LT cases. While $71.8 \%(n=827)$ of LDLT patients were hepatitis B-related, only $58.3 \%(n=208)$ of DDLTs were hepatitis B-related. While $10.0 \%(n=115)$ of LDLTs were alcohol-related, $26.1 \%(n=93)$ of DDLTs were alcohol-related. While more than half $(n=670,58.1 \%)$ of LDLT patients were HCC patients, only $38.4 \%(n=138)$ of DDLTs were HCC patients. Number of ABO incompatible LDLTs were 149 ( $n=12.9 \%$ ). Mean MEAF score was $5.77 \pm 1.66$ in the LDLT cases compared to $7.12 \pm 1.58$ in DDLT cases. While $21.0 \%$ $(n=242)$ of LDLT cases met the EAD criteria, $35.4 \%(n=127)$ of DDLT cases met the EAD criteria.

\section{Prediction model using multivariable Cox regression}

To build the best model for prediction, laboratory values were analyzed using univariable and multivariable models. Log 2 -transformation was performed to increase the predictability by changing the variable to a normal distribution.

Table 2 summarizes the results of the Cox regression models for LDLT. MEAF score as a continuous variable was significantly related to graft survival $(\mathrm{HR}=1.56, \mathrm{Cl}=1.35-1.80, \mathrm{P}<0.001)$. EAD criteria as a binary variable was significantly related to graft survival $(\mathrm{HR}=3.28, \mathrm{Cl}=2.14-5.03, \mathrm{P}<0.001)$. In the univariate analysis, $\log _{2}$-transformed $\mathrm{AST}_{\max 7}(\mathrm{HR}=1.87, \mathrm{Cl}=1.60-2.18, \mathrm{P}<0.001), \log _{2}$-transformed $\mathrm{TB}_{\max 3-7}(\mathrm{HR}=1.62, \mathrm{Cl}=1.40-1.89, \mathrm{P}<0.001)$ and $\log _{2}{ }^{-}$ transformed INR $\operatorname{max3-7}_{\text {m }}(\mathrm{HR}=3.99, \mathrm{Cl}=2.99-5.32, \mathrm{P}<0.001)$ were related to graft survival. The $\mathrm{ABC}$ model for LDLT were constructed using three variables; $\log _{2}$-transformed $A S T_{\max 7}(H R=1.52, C l=1.29-1.80, P<0.001), \log _{2}$-transformed $T_{B_{\text {max3-7 }}}(H R=1.44, C l=1.23-1.70, P<0.001)$ and log ${ }_{2}$-transformed INR max3-7 $(\mathrm{HR}=3.29, \mathrm{Cl}=2.20-4.90, \mathrm{P}<0.001)$.

C-index and time-dependent AUCs at 2 weeks and 4 weeks were compared between the ABC model and the other two models. The C-index of the ABC model for LDLT (0.73, $\mathrm{Cl}=0.67-0.79)$ were higher compared to $\mathrm{C}$-indexes of MEAF score $(0.69, \mathrm{Cl}=0.63-0.76, \mathrm{P}=0.03)$ and $\mathrm{EAD}$ criteria $(0.64, \mathrm{Cl}=0.59-0.83$, $\mathrm{P}=0.001)$. Time-dependent $A U C$ at 2 weeks of the $A B C$ model $(A U C=0.96, C l=0.91-1.00)$ was significantly higher compared to that of $E A D$ criteria ( $A U C=0.83, \mathrm{Cl}=0.75-0.92, \mathrm{P}<0.001)$, while there was no significant difference compared to that of MEAF score. $(A U C=0.90, C l=0.81-0.99, P=0.09, F i g u r e 1 A)$ Time-dependent AUC at 4 weeks of the $A B C$ model $(A U C=0.93, C U=0.86-0.99)$ was significantly higher compared to those of $M E A F$ score $(A U C=0.87$, $\mathrm{Cl}=0.78-0.95, \mathrm{P}=0.02)$ and $\mathrm{EAD}$ criteria ( $\mathrm{AUC}=0.84, \mathrm{Cl}=0.78-0.91, \mathrm{P}=0.02$, Figure $1 \mathrm{~B})$.

Table 3 summarizes the results of the Cox regression models for DDLT. MEAF score as a continuous variable was significantly related to graft survival $(\mathrm{HR}=1.65, \mathrm{Cl}=1.32-2.06, \mathrm{P}<0.001)$. EAD criteria as a binary variable was significantly related to graft survival $(\mathrm{HR}=2.99, \mathrm{Cl}=1.66-5.37, \mathrm{P}<0.001)$. In the

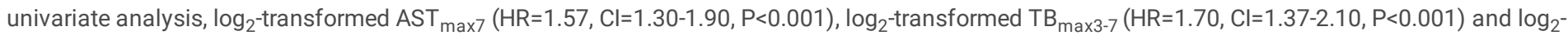


transformed INR $\operatorname{max3-7}(\mathrm{HR}=5.56, \mathrm{Cl}=3.46-8.94, \mathrm{P}<0.001)$ were related to graft survival. The $\mathrm{ABC}$ model for DDLT were constructed using three variables; $\log _{2}$-transformed AST $\max 7(H R=1.19, C l=0.96-1.47, P<0.11), \log _{2}$-transformed $T_{B_{\text {max3-7 }}}(H R=1.35, C l=1.05-1.73, P=0.02)$ and log ${ }_{2}$-transformed INR max3-7 $(\mathrm{HR}=3.07, \mathrm{Cl}=1.67-5.64, \mathrm{P}<0.001)$.

C-index and time-dependent AUCs at 2 weeks and 4 weeks were compared between the ABC model and the other two models. The C-index of the ABC model for $\operatorname{DDLT}(0.74, \mathrm{Cl}=0.65-0.83)$ was higher compared to $\mathrm{C}$-index of EAD criteria $(0.66, \mathrm{Cl}=0.59-0.73, \mathrm{P}=0.002)$ whereas difference with $\mathrm{MEAF}$ score was statistically insignificant $(0.71, \mathrm{Cl}=0.62-0.80, \mathrm{P}=0.31)$. Time-dependent $\mathrm{AUC}$ at 2 weeks of the $\mathrm{ABC}$ model $(\mathrm{AUC}=0.98, \mathrm{Cl}=0.96-0.99)$ was significantly higher compared to that of EAD criteria ( $A U C=0.83, C l=0.81-0.86, P<0.001$ ), while there was no significant difference compared to that of $M E A F$ score. ( $A U C=0.88, \mathrm{Cl}=0.77-0.99, \mathrm{P}=0.08$, Figure $1 \mathrm{C}$ ) Time-dependent $\mathrm{AUC}$ at 4 weeks of the $\mathrm{ABC}$ model $(\mathrm{AUC}=0.94, \mathrm{CU}=0.89-1.00)$ was significantly higher compared to those of MEAF score $(A U C=0.82, C l=0.68-0.96, P=0.02)$ and $E A D$ criteria $(A U C=0.81, C l=0.74-0.88, P<0.001, F i g u r e 1 D)$.

The predicted survival probabilities from Cox proportional hazards model for a set of covariates X may be estimated by the equation below where $S_{0}(t)$ is Breslow estimator for baseline survival function.

$S(t, x)=S_{0}(t) \exp (\times \beta)$

$S_{0}(t)=$ baseline survival function

$x \beta=\left\{\left(\log _{2} \mathrm{AST}_{\max 7} \times 0.4205\right)+\left(\log _{2} \mathrm{~TB}_{\operatorname{max3-7}} \times 0.3656\right)+\left(\log _{2} \mathrm{INR}_{\operatorname{max3-7}} \times 1.1893\right)\right\}-5.11$ for LDLT

$x \beta=\left\{\left(\log _{2} A S T_{\max 7} \times 0.1751\right)+\left(\log _{2} T B_{\max 3-7} \times 0.2986\right)+\left(\log _{2} I N R_{\max 3-7} \times 1.1205\right)\right\}-3.28$ for DDLT

The baseline survival function is presented as tables in Supplementary table 1 and 2 . The predicted probability of the recipient in a certain time point or the survival plot using the $\mathrm{ABC}$ model can be performed by putting the laboratory values into the Excel document provided as Supplementary material.

\section{Apparent validation and internal validation}

For internal validation, 20-time repeated 5-fold cross validation was applied to evaluate their performance. Apparent validation of the ABC model for LDLT showed C-index of 0.73 ( $\mathrm{Cl}=0.69-0.79)$, AUC at 2 weeks of $0.96(\mathrm{Cl}=0.91-1.00)$, and AUC at 4 weeks of 0.93 ( $\mathrm{Cl}=0.86-0.99)$. Internal validation using 20-time repeated 5-fold cross validation of the ABC model for LDLT showed C-index of $0.68(\mathrm{Cl}=0.66-0.69)$, AUC at 2 weeks of 0.91 ( $\mathrm{Cl}=0.87-0.96)$, and AUC at 4 weeks of 0.92 ( $\mathrm{Cl}=0.91-0.94)$. Apparent validation of the $\mathrm{ABC}$ model for DDLT showed C-index of $0.74(\mathrm{Cl}=0.65-0.83), \mathrm{AUC}$ at 2 weeks of 0.98 $(\mathrm{Cl}=0.96-1.00)$, and AUC at 4 weeks of $0.94(\mathrm{Cl}=0.89-1.00)$. Internal validation using 20-time repeated 5-fold cross validation of the ABC model for DDLT showed C-index of 0.68 ( $\mathrm{Cl}=0.66-0.70)$, AUC at 2 weeks of $0.86(\mathrm{Cl}=0.80-0.92)$, and AUC at 4 weeks of $0.91(\mathrm{Cl}=0.87-0.94)$.

\section{Calibration plot}

Calibration plots of $A B C$ models at 2 weeks and 4 weeks through 1000 bootstrap resamples were performed. Figure 2 shows the calibration plots of $A B C$ models for both LDLT and DDLT. The predicted probability and actual survival probability showed relatively competent calibration for ABC models for LDLT and DDLT.

\section{Decision curve analysis}

To evaluate the clinical usefulness of $A B C$ model, decision curves were computed to calculate the net benefit. Figure 3 shows the decision curves of $A B C$ models for LDLT and DDLT. For both 2 weeks and 4 weeks, and for both LDLT and DDLT, the decision curve constantly calculated above the zero-benefit line, showing beneficial expectation of the models.

\section{Time-dependent AUC curves of ABC model}

Time-dependent AUC curves of ABC models were illustrated in Figure 4. When the reference line was set as AUC of 0.75 , the time-dependent AUCs were calculated to be above the reference line until 1 year in LDLT, and around 250 days in DDLT.

\section{Discussion}

Due to improvement in surgical skills, optimization of immunosuppression, and postoperative intensive care, the outcome of LT has improved throughout the decades, and graft failure rate has significantly decreased. However, there are still recipients who experience graft dysfunction and require appropriate decision making to undergo re-transplantation. Nevertheless, new competent liver grafts for those experiencing graft dysfunction are not always available, creating an urgent need for re-transplant criteria. The criteria of OPTN are utilized as guidance in allocating deceased donor livers although they are limited in allocating new grafts for patients with potential graft failure. Several studies have built a prediction model for graft failure. Although such studies showed improvement in prediction, there is no consensus on a definite model for predicting graft failure. This study was designed to build a prediction model for graft survival using simplified variables among the largest studied cohort.

Nonfunctioning livers usually show a similar pattern of laboratory values. AST and ALT peak at day 1 and 2 post-LT, respectively, and gradually decrease thereafter; there can be additional peaks when the graft is injured by mechanisms such as hypotension. The pattern is similar in successful grafts, but 
maximum AST and ALT indicate extent of graft injury. On the other hand, TB level changes slowly and gradually increases along the clinical course in failing grafts. The initial TB level is dependent on pre-LT TB level and transfusions, which are performed intensely during the initial post-LT period. Therefore, both successful and failing LTs show a decreasing pattern in the initial period, while failing LTs then show gradual increase. Patterns of INR level are most similar between successful and failing grafts, although the levels are higher in nonfunctioning grafts and remain higher during the post-LT course. However, the time point and level of the peak may vary among LT cases. Therefore, peak AST after LT and maximum TB and INR after the early post-LT period are important regardless of day. This is why we built a model to choose the maximum AST of the post-LT period and maximum values of TB and INR starting from day 3 post-LT.

ABC model was built based on LT data from 1153 LDLT and 359 DDLTs. The AUCs of the prediction models were 0.96 and 0.98 in predicting graft failure within 2 weeks and 0.93 and 0.94 in predicting graft failure within 4 weeks, for LDLT and DDLT, respectively. ABC model is also very intuitive by including the maximum values of AST, TB, and INR during the first week and during the first 2 weeks for predicting graft failure within 2 weeks and 4 weeks, respectively. The model was compared to previously published models, such as MEAF score and EAD criteria. By comparing the C-index and timedependent AUC at 2 weeks and 4 weeks, $A B C$ model showed superior outcome compared to the other two models.

Prediction probability can be calculated easily if the clinician knows the maximum AST, TB, and INR during the post-LT period, by inserting the values to our supplementary Excel document, which is well-calibrated to the retrospective cohort of our institution.

The limitation of our study is that it is based on data from a single institution. The model was based on a cohort of was performed predominantly with LDLTs and number of cases included in the DDLT model was 359 cases. Nevertheless, our study showed high validity during internal validation; therefore, good results during external validation with other cohorts is expected.

The currently applied criteria for primary nonfunction as suggested by OPTN served as a good decision tool. However, the criteria were quite restrictive; in countries like the Republic of Korea where donation from deceased donors is relatively lower than in other countries, many patients with graft failure are unable to undergo re-LT. Our prediction model provides objective data on the probability of graft survival, which can guide patient selection in those requiring urgent re-LT even the first week after LT.

\section{Abbreviations}

Liver transplantation LT

Organ Procurement and Transplant Network OPTN

Aspartate aminotransferase AST

International normalized ratio INR

Total bilirubin TB

Early allograft dysfunction EAD

Modeling early allograft function MEAF

Living donor liver transplantation LDLT

Deceased donor liver transplantation DDLT

Area-under-the-curve AUC

Receiver-operating-characteristics ROC

Confidence interval $\mathbf{C l}$

Interquartile range IQR

Hazard ratio OR

\section{Declarations}

Acknowledgement: The data that supports the findings of this study are available in the supplementary material of this article

\section{Author Contribution}

Jinsoo Rhu, M.D.: Participated in research design, writing of the paper, data analysis

Jong Man Kim M.D., Ph.D.: Participated in research design, writing of the paper, data analysis 
Gyu-Seong Choi, M.D., Ph.D.: Participated in research design

Jae-Won Joh M.D., Ph.D.: Participated in research design

Kyunga Kim, Ph.D. : Participated in research design, data analysis

Heejin Yoo : Participated in research design, data analysis

Funding: This study is not related to any kind of financial funding

Conflict of interest statement: The authors declare no conflict of interests related to the study.

\section{References}

1. Makowka, L. et al. Analysis of donor criteria for the prediction of outcome in clinical liver transplantation. Transplant Proc. 19, 2378-2382 (1987).

2. Mor, E. et al. The use of marginal donors for liver transplantation. A retrospective study of 365 liver donors. Transplantation. 53, 383-386 (1992).

3. Ploeg, R. J. et al. Risk factors for primary dysfunction after liver transplantation-a multivariate analysis. Transplantation. 55, 807-813 (1993).

4. OPTN. Allocation of Livers and Liver-Intestines. (2019).

5. Al-Freah, M. A. B. et al. Improving the Diagnostic Criteria for Primary Liver Graft Nonfunction in Adults Utilizing Standard and Transportable Laboratory Parameters: An Outcome-Based Analysis. Am J Transplant. 17, 1255-1266 (2017).

6. Ardite, E., Ramos, C., Rimola, A., Grande, L. \& Fernandez-Checa, J. C. Hepatocellular oxidative stress and initial graft injury in human liver transplantation. J Hepatol. 31, 921-927 (1999).

7. Ben-Ari, Z. et al. Serum cholestasis markers as predictors of early outcome after liver transplantation. Clin Transplant. 18, 130-136 (2004).

8. Carraro, P. et al. Laboratory test scores to aid identification of primary nonfunction of liver transplants. Clin Chem. 41, 471 (1995).

9. Gonzalez, F. X. et al. Predictive factors of early postoperative graft function in human liver transplantation. Hepatology. 20, 565-573 (1994).

10. Strasberg, S. M., Howard, T. K., Molmenti, E. P. \& Hertl, M. Selecting the donor liver: risk factors for poor function after orthotopic liver transplantation. Hepatology. 20, 829-838 (1994).

11. Deschenes, M., Belle, S. H., Krom, R. A., Zetterman, R. K. \& Lake, J. R. Early allograft dysfunction after liver transplantation: a definition and predictors of outcome. National Institute of Diabetes and Digestive and Kidney Diseases Liver Transplantation Database. Transplantation. 66, 302-310 (1998).

12. Briceno, J. \& Ciria, R. Early graft dysfunction after liver transplantation. Transplant Proc. 42, 631-633 (2010).

13. Nanashima, A. et al. Analysis of initial poor graft function after orthotopic liver transplantation: experience of an australian single liver transplantation center. Transplant Proc. 34, 1231-1235 (2002).

14. Olthoff, K. M. et al. Validation of a current definition of early allograft dysfunction in liver transplant recipients and analysis of risk factors. Liver Transpl. 16, 943-949 (2010).

15. Pareja, E. et al. A score model for the continuous grading of early allograft dysfunction severity. Liver Transpl. 21, 38-46 (2015).

16. Uno, H., Cai, T., Pencina, M. J., D'Agostino, R. B. \& Wei, L. J. On the C-statistics for evaluating overall adequacy of risk prediction procedures with censored survival data. Stat Med. 30, 1105-1117 (2011).

\section{Tables}

Table 1. Baseline characteristics and postoperative graft failures of adult liver transplantation patients. 


\begin{tabular}{|c|c|c|}
\hline Variables & $\begin{array}{l}\text { Living donor } \\
(\mathrm{N}=1153)\end{array}$ & $\begin{array}{l}\text { Deceased donor } \\
(\mathrm{N}=359)\end{array}$ \\
\hline Recipient sex (Male/female) & $899 / 254(78.0 \%)$ & $241 / 118(67.1 \%)$ \\
\hline Recipient mean age (years) & $52.8 \pm 8.5$ & $51.7 \pm 10.4$ \\
\hline Donor sex (Male/female) & 746/407 (64.7\%) & $236 / 123(65.7 \%)$ \\
\hline Donor mean age (years) & $32.7 \pm 11.6$ & $46.9 \pm 16.3$ \\
\hline Re-transplantation & $10(0.9 \%)$ & $49(13.7 \%)$ \\
\hline \multicolumn{3}{|l|}{ Etiology } \\
\hline Hepatitis B virus & $827(71.8 \%)$ & $208(58.4 \%)$ \\
\hline Hepatitis $C$ virus & $67(5.8 \%)$ & $7(2.0 \%)$ \\
\hline Alcohol & $115(10.0 \%)$ & $93(26.1 \%)$ \\
\hline Others & $143(12.4 \%)$ & $48(13.5 \%)$ \\
\hline Hepatocellular carcinoma & $670(58.1 \%)$ & $138(38.4 \%)$ \\
\hline ABO incompatible & $149(12.9 \%)$ & - \\
\hline Graft weight (g) & $676.1 \pm 196.5$ & $1173.7 \pm 624.8$ \\
\hline Graft-recipient weight ratio & $1.00 \pm 0.34$ & $1.74 \pm 1.02$ \\
\hline Graft failure & $85(7.4 \%)$ & $46(12.8 \%)$ \\
\hline within 2 weeks & $16(1.4 \%)$ & $10(2.8 \%)$ \\
\hline within 4 weeks & $26(2.3 \%)$ & $16(4.5 \%)$ \\
\hline within 2 months & $34(2.9 \%)$ & $21(5.8 \%)$ \\
\hline Median follow up days & $1740(541-3370)$ & 1112 (274-2489) \\
\hline \multicolumn{3}{|l|}{ Median AST (U/L) on the } \\
\hline day of LT & $247(167-364)$ & $88(54-346)$ \\
\hline $1^{\text {st }}$ post-LT day & $286(196-453)$ & $766.5(443-996)$ \\
\hline $2^{\text {nd }}$ post-LT day & $179(95-316)$ & $471(214-868)$ \\
\hline $3^{\text {rd }}$ post-LT day & $92(74-168)$ & $230(86-582)$ \\
\hline 5 pust-Li uay & $69(50-91)$ & $88(56-252)$ \\
\hline $4^{\text {th }}$ post-LT day & $55(40-78)$ & $62(38-94)$ \\
\hline $5^{\text {th }}$ post-LT day & $50(37-72)$ & $43(30-75)$ \\
\hline $6^{\text {th }}$ post-LT day & $47(34-69)$ & $39(25-61)$ \\
\hline \multicolumn{3}{|l|}{$7^{\text {th }}$ post-LT day } \\
\hline \multicolumn{3}{|l|}{ Median TB $(\mathrm{mg} / \mathrm{dL})$ on the } \\
\hline day of LT & $4.2(2.7-7.1)$ & $14.1(5.1-31.9)$ \\
\hline $1^{\text {st }}$ post-LT day & $4.2(2.4-7.2)$ & $8.15(5.1-9.8)$ \\
\hline $2^{\text {nd }}$ post-LT day & $2.6(1.5-4.8)$ & $6.1(3-9.5)$ \\
\hline $3^{\text {rd }}$ post-LT day & $2.3(1.5-4.6)$ & $5.1(2.5-9.4)$ \\
\hline & $2.2(1.4-4.5)$ & $4.5(2.2-8.9)$ \\
\hline $4^{\text {th }}$ post-LT day & $2.1(1.4-4.4)$ & $4.2(2-7.6)$ \\
\hline $5^{\text {th }}$ post-LT day & $2(1.3-4.1)$ & $3.7(1.8-6.6)$ \\
\hline $6^{\text {th }}$ post-LT day & $2.1(1.3-4.2)$ & $3.5(1.7-6.3)$ \\
\hline $7^{\text {th }}$ post-LT day & & \\
\hline \multicolumn{3}{|l|}{ Median PT/INR on the } \\
\hline Day of LT & $3.38(2.57-4.48)$ & $3.63(2.77-4.84)$ \\
\hline
\end{tabular}

Page $7 / 12$ 


\begin{tabular}{|lll|}
$1^{\text {st }}$ post-LT day & $2.62(2.22-3.20)$ & $3.26(2.32-4.30)$ \\
$2^{\text {nd }}$ post-LT day & $2.02(1.74-2.34)$ & $1.57(1.38-2.05)$ \\
$3^{\text {rd }}$ post-LT day & $1.58(1.42-1.80)$ & $1.42(1.28-1.71)$ \\
$4^{\text {th }}$ post-LT day & $1.47(1.34-1.66)$ & $1.38(1.26-1.58)$ \\
$5^{\text {th }}$ post-LT day & $1.40(1.27-1.58)$ & $1.35(1.22-1.51)$ \\
$6^{\text {th }}$ post-LT day & $1.36(1.24-1.54)$ & $1.32(1.19-1.46)$ \\
$7^{\text {th }}$ post-LT day & $1.31(1.19-1.46)$ & $1.26(1.16-1.41)$ \\
\hline Mean MEAF score & & \\
\hline Early allograft dysfunction criteria (one of more of the following) & $242(21.0 \%)$ & $127(35.4 \%)$ \\
AST or ALT $\geq 2000 ~ U / L$ within the first 7 days & $58(5.0 \%)$ & $97(27.0 \%)$ \\
TB on $7^{\text {th }}$ post-LT day $\geq 10 \mathrm{mg} / \mathrm{dL}$ & $82(7.1 \%)$ & $44(12.3 \%)$ \\
\hline PT/INR on 7th post-LT day $\geq 1.60$ & $150(13.0 \%)$ & $40(11.1 \%)$ \\
\hline
\end{tabular}

Model for early allograft function MEAF; International normalized ratio INR; Total bilirubin TB; Aspartate aminotransferase AST; Alanine aminotransferase ALT

Table 2. Comparisons of C-index, time-dependent AUC at 2 weeks, and time-dependent AUC at 4 weeks between Cox proportional hazard regression models using MEAF score, EAD criteria and newly developed multivariable model for predicting graft survival of recipients who underwent living donor liver transplantation.

\begin{tabular}{|c|c|c|c|c|c|c|c|c|c|c|c|c|c|}
\hline Models & Variables & $\mathrm{HR}$ & $\begin{array}{l}95 \% \\
\mathrm{Cl}\end{array}$ & $\mathrm{P}$ & $\begin{array}{l}\text { C- } \\
\text { index }\end{array}$ & $\begin{array}{l}95 \% \\
\mathrm{Cl}\end{array}$ & $\begin{array}{l}\text { P- } \\
\text { value } \\
\text { vs. } \\
\text { ABC } \\
\text { model }\end{array}$ & $\begin{array}{l}\text { Time- } \\
\text { dependent } \\
\text { AUC at } \\
2 \text { weeks }\end{array}$ & $\begin{array}{l}95 \% \\
\mathrm{Cl}\end{array}$ & $\begin{array}{l}\text { P- } \\
\text { value } \\
\text { vs. } \\
\text { ABC } \\
\text { model }\end{array}$ & $\begin{array}{l}\text { Time- } \\
\text { dependent } \\
\text { AUC at } \\
4 \text { weeks }\end{array}$ & $\begin{array}{l}95 \% \\
\mathrm{Cl}\end{array}$ & $\begin{array}{l}\text { P- } \\
\text { value } \\
\text { vs. } \\
\text { ABC } \\
\text { model }\end{array}$ \\
\hline MEAF score & & 1.56 & $\begin{array}{l}1.35- \\
1.80\end{array}$ & $<0.001$ & 0.69 & $\begin{array}{l}0.63- \\
0.76\end{array}$ & 0.03 & 0.90 & $\begin{array}{l}0.81- \\
0.99\end{array}$ & 0.09 & 0.87 & $\begin{array}{l}0.78- \\
0.95\end{array}$ & 0.02 \\
\hline EAD criteria & & 3.28 & $\begin{array}{l}2.14- \\
5.04\end{array}$ & $<0.001$ & 0.64 & $\begin{array}{l}0.59- \\
0.83\end{array}$ & 0.001 & 0.83 & $\begin{array}{l}0.75- \\
0.92\end{array}$ & $<0.001$ & 0.84 & $\begin{array}{l}0.78- \\
0.91\end{array}$ & 0.02 \\
\hline \multirow[t]{3}{*}{ Univariable } & $\log _{2}\left(\mathrm{AST}_{\max 7}\right)$ & 1.87 & $\begin{array}{l}1.60- \\
2.18\end{array}$ & $<0.001$ & & & & & & & & & \\
\hline & $\log _{2}\left(\mathrm{~TB}_{\operatorname{max3-7}}\right)$ & 1.62 & $\begin{array}{l}1.40- \\
1.89\end{array}$ & $<0.001$ & & & & & & & & & \\
\hline & $\begin{array}{l}\log _{2}\left(\mathrm{INR}_{\operatorname{max3}-}\right. \\
7)\end{array}$ & 3.99 & $\begin{array}{l}2.99- \\
5.32\end{array}$ & $<0.001$ & & & & & & & & & \\
\hline \multirow[t]{3}{*}{$\begin{array}{l}\text { Multivariable } \\
\text { ABC model }\end{array}$} & $\log _{2}\left(\mathrm{AST}_{\max 7}\right)$ & 1.52 & $\begin{array}{l}1.29- \\
1.80\end{array}$ & $<0.001$ & 0.73 & $\begin{array}{l}0.67- \\
0.79\end{array}$ & & 0.96 & $\begin{array}{l}0.91- \\
1.00\end{array}$ & & 0.93 & $\begin{array}{l}0.86- \\
0.99\end{array}$ & \\
\hline & $\log _{2}\left(\mathrm{~TB}_{\operatorname{max3-7}}\right)$ & 1.44 & $\begin{array}{l}1.23- \\
1.70\end{array}$ & $<0.001$ & & & & & & & & & \\
\hline & $\begin{array}{l}\log _{2}\left(\mathrm{INR}_{\operatorname{max3}}\right. \\
7)\end{array}$ & 3.29 & $\begin{array}{l}2.20- \\
4.90\end{array}$ & $<0.001$ & & & & & & & & & \\
\hline
\end{tabular}

Hazard ratio HR; area under the curve AUC; confidence interval Cl; Modeling Early Allograft Function MEAF; early allograft dysfunction EAD; aspartate aminotransferase AST; total bilirubin TB; international normalized ratio INR

Table 3. Comparisons of C-index, time-dependent AUC at 2 weeks, and time-dependent AUC at 4 weeks between Cox proportional hazard regression models using MEAF score, EAD criteria and newly developed multivariable model for predicting graft survival of recipients who underwent deceased donor liver transplantation. 


\begin{tabular}{|c|c|c|c|c|c|c|c|c|c|c|c|c|c|}
\hline Models & Variables & $\mathrm{HR}$ & $\begin{array}{l}95 \% \\
\mathrm{Cl}\end{array}$ & $\mathrm{P}$ & $\begin{array}{l}\text { C- } \\
\text { index }\end{array}$ & $\begin{array}{l}95 \% \\
\mathrm{Cl}\end{array}$ & $\begin{array}{l}\text { P- } \\
\text { value } \\
\text { vs. } \\
\text { model }\end{array}$ & $\begin{array}{l}\text { Time- } \\
\text { dependent } \\
\text { AUC at } \\
2 \text { weeks }\end{array}$ & $\begin{array}{l}95 \% \\
\mathrm{Cl}\end{array}$ & $\begin{array}{l}\text { P- } \\
\text { value } \\
\text { vs. } \\
\text { model }\end{array}$ & $\begin{array}{l}\text { Time- } \\
\text { dependent } \\
\text { AUC at } \\
4 \text { weeks }\end{array}$ & $\begin{array}{l}95 \% \\
\mathrm{Cl}\end{array}$ & $\begin{array}{l}\text { P- } \\
\text { value } \\
\text { vs. } \\
\text { model }\end{array}$ \\
\hline MEAF score & & 1.65 & $\begin{array}{l}1.32- \\
2.06\end{array}$ & $<0.001$ & 0.71 & $\begin{array}{l}0.62- \\
0.80\end{array}$ & 0.31 & 0.88 & $\begin{array}{l}0.77- \\
0.99\end{array}$ & 0.08 & 0.82 & $\begin{array}{l}0.68- \\
0.96\end{array}$ & 0.02 \\
\hline EAD criteria & & 2.99 & $\begin{array}{l}1.66- \\
5.37\end{array}$ & $<0.001$ & 0.66 & $\begin{array}{l}0.59- \\
0.73\end{array}$ & 0.002 & 0.83 & $\begin{array}{l}0.81- \\
0.86\end{array}$ & $<0.001$ & 0.81 & $\begin{array}{l}0.74- \\
0.88\end{array}$ & $<0.001$ \\
\hline \multirow[t]{3}{*}{ Univariable } & $\log _{2}\left(\mathrm{AST}_{\max 7}\right)$ & 1.57 & $\begin{array}{l}1.30- \\
1.90\end{array}$ & $<0.001$ & & & & & & & & & \\
\hline & $\log _{2}\left(\mathrm{~TB}_{\operatorname{max3-7}}\right)$ & 1.70 & $\begin{array}{l}1.37- \\
2.10\end{array}$ & $<0.001$ & & & & & & & & & \\
\hline & $\begin{array}{l}\log _{2}\left(\mathrm{INR}_{\max 3-}\right. \\
7)\end{array}$ & 5.56 & $\begin{array}{l}3.46- \\
8.94\end{array}$ & $<0.001$ & & & & & & & & & \\
\hline \multirow[t]{3}{*}{$\begin{array}{l}\text { Multivariable } \\
\text { model }\end{array}$} & $\log _{2}\left(\mathrm{AST}_{\max 7}\right)$ & 1.19 & $\begin{array}{l}0.96- \\
1.47\end{array}$ & 0.11 & 0.74 & $\begin{array}{l}0.65- \\
0.83\end{array}$ & & 0.98 & $\begin{array}{l}0.96- \\
1.00\end{array}$ & & 0.94 & $\begin{array}{l}0.89- \\
1.00\end{array}$ & \\
\hline & $\log _{2}\left(\mathrm{~TB}_{\operatorname{max3-7}}\right)$ & 1.35 & $\begin{array}{l}1.05- \\
1.73\end{array}$ & 0.02 & & & & & & & & & \\
\hline & $\begin{array}{l}\log _{2}\left(I R_{\max 3-}-\right. \\
7)\end{array}$ & 3.07 & $\begin{array}{l}1.67- \\
5.64\end{array}$ & $<0.001$ & & & & & & & & & \\
\hline
\end{tabular}

Hazard ratio HR; area under the curve AUC; confidence interval Cl; Modeling Early Allograft Function MEAF; early allograft dysfunction EAD; aspartate aminotransferase AST; total bilirubin TB; international normalized ratio INR

\section{Figures}



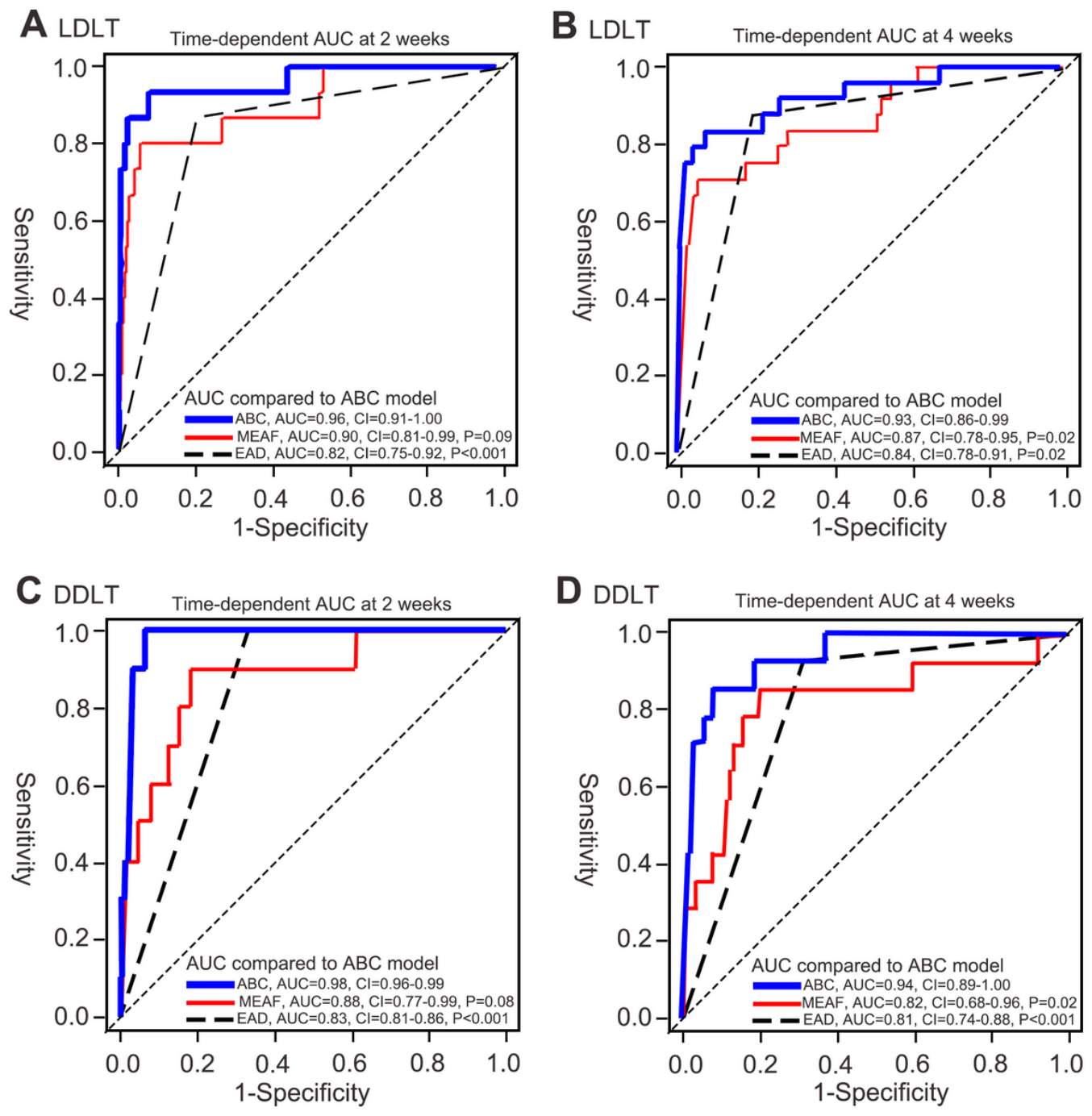

Figure 1

Comparison of time-dependent AUCs of ABC model, MEAF score and EAD criteria. (A) Time-dependent AUC at 2 weeks for LDLT. (B) Time-dependent AUC at 4 weeks for LDLT. (C) Time-dependent AUC at 2 weeks for DDLT. (D) Time-dependent AUC at 4 weeks for DDLT. The P-values presented are comparison of AUC of MEAF score and EAD criteria against that of $A B C$ model. 
A LDLT

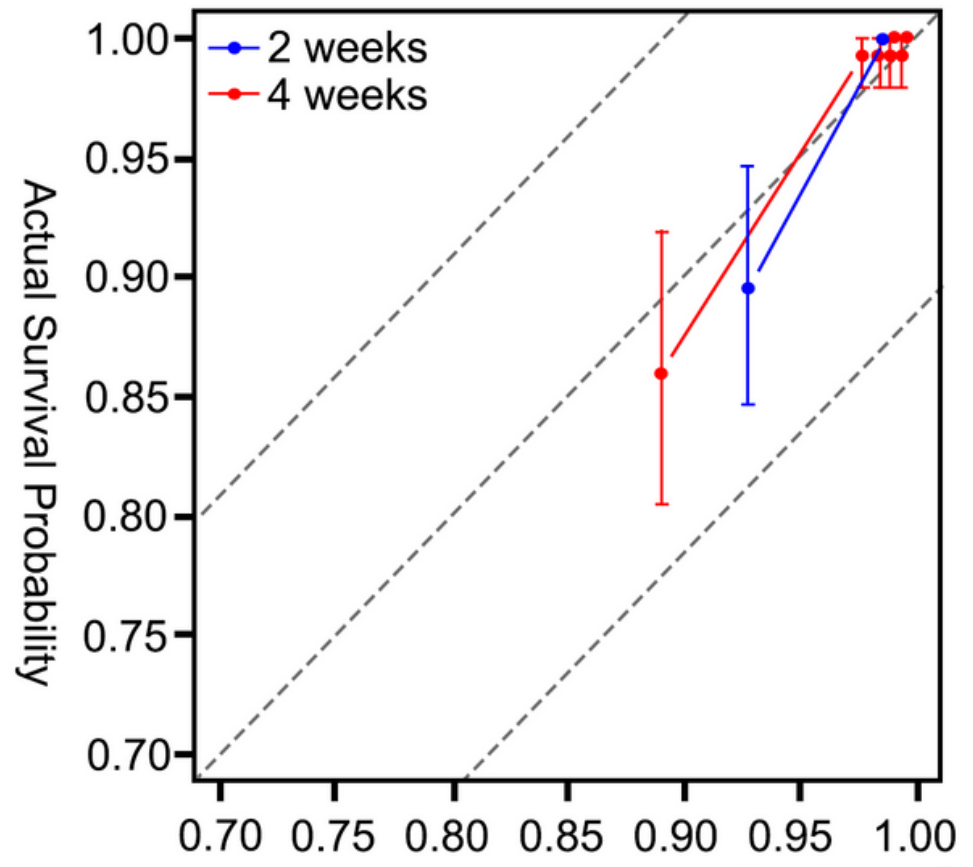

B DDLT

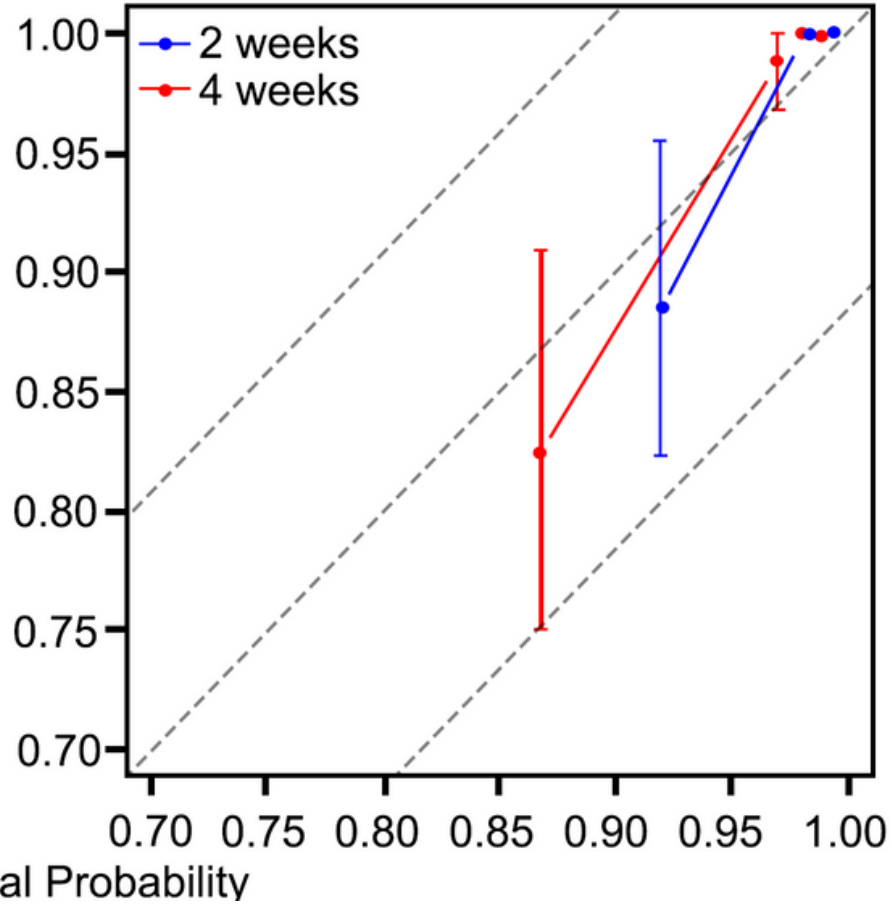

Figure 2

Calibration plots of ABC models for predicting graft survival within 2 weeks and 4 weeks (A) in LDLT cases (B) and DDLT cases.

A LDLT

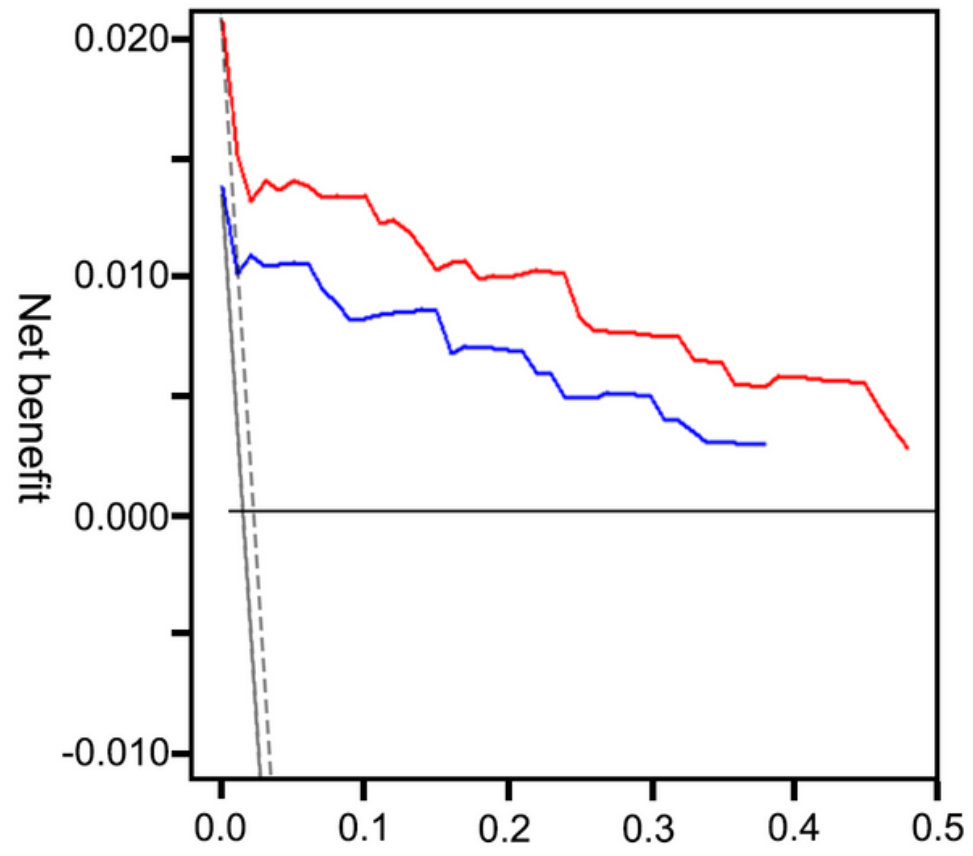

B DDLT

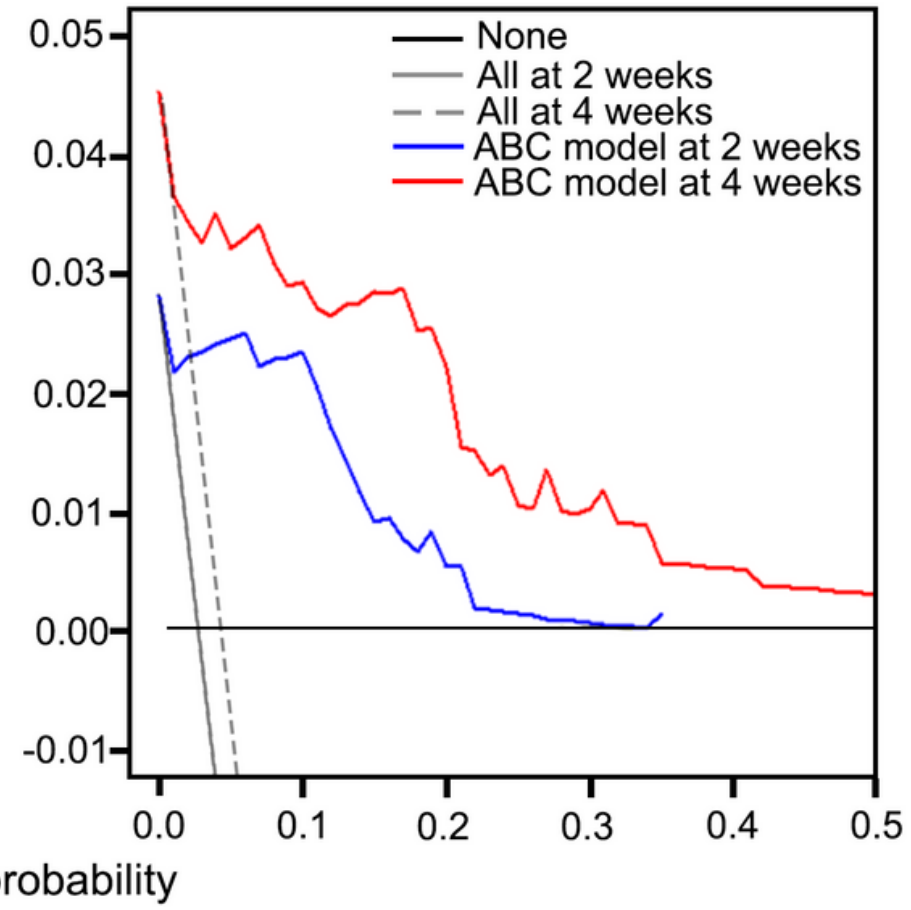

Figure 3

Decision curves of $A B C$ models for predicting graft survival within 2 weeks and 4 weeks $(A)$ in LDLT cases (B) and DDLT cases. 
A LDLT

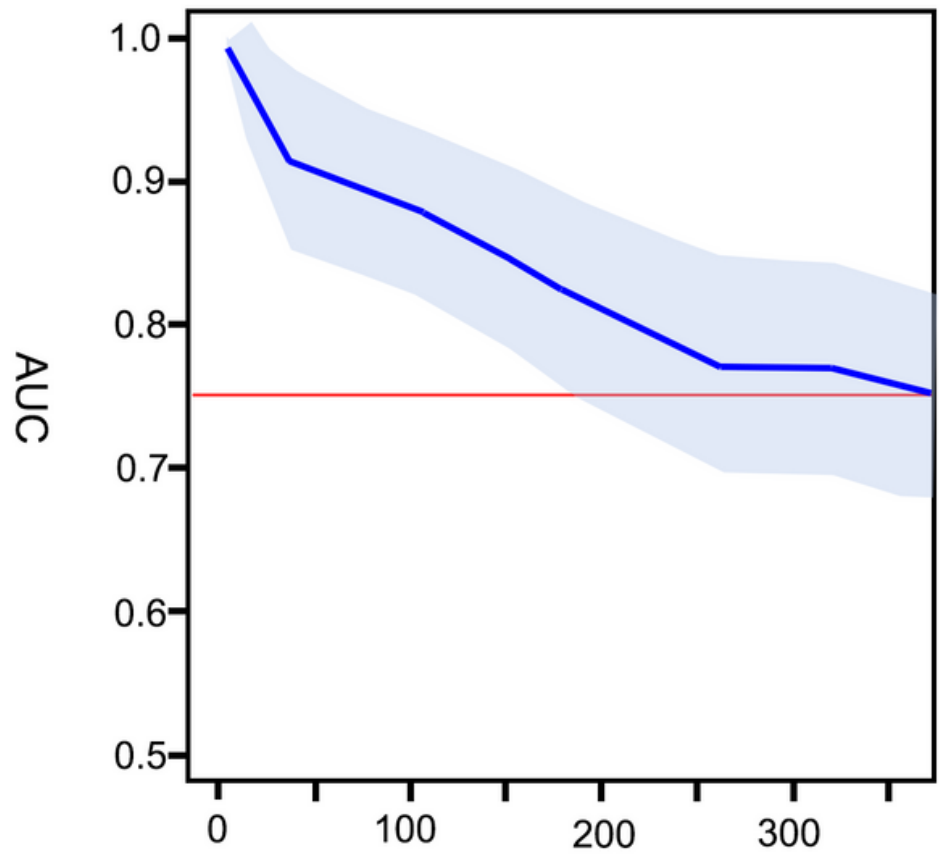

B DDLT

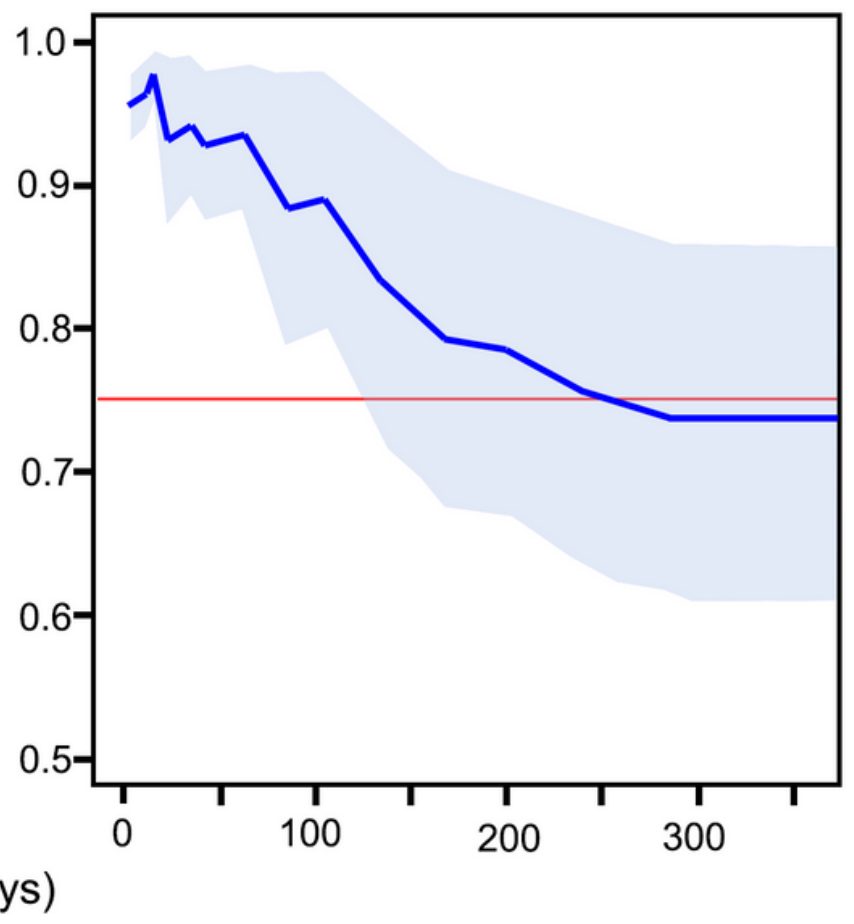

Figure 4

Time-dependent AUC curves during the 1-year post-transplantation period (A) in LDLT cases (B) and DDLT cases.

\section{Supplementary Files}

This is a list of supplementary files associated with this preprint. Click to download.

- Supplementarymaterial.docx 